Review

\title{
The Regulatory Role of Signaling Crosstalk in Hypertrophy of MSCs and Human Articular Chondrocytes
}

\author{
Leilei Zhong ${ }^{1, \dagger}$, Xiaobin Huang ${ }^{1,2, \dagger}$, Marcel Karperien ${ }^{1}$ and Janine N. Post ${ }^{1, *}$ \\ 1 Developmental BioEngineering, MIRA Institute for Biomedical Technology and Technical Medicine, \\ University of Twente, Enschede 7500 AE, The Netherlands; E-Mails: 1.zhong@utwente.nl (L.Z.); \\ xiaobinhuang@cqu.edu.cn (X.H.); h.b.j.karperien@utwente.nl (M.K.) \\ 2 School of Life Sciences, Chongqing University, Chongqing 400030, China \\ $\dagger$ These authors contributed equally to this work. \\ * Author to whom correspondence should be addressed; E-Mail: j.n.post@utwente.nl; \\ Tel.: +31-53-4894205.
}

Academic Editors: Charles J. Malemud and Ali Mobasheri

Received: 7 July 2015 / Accepted: 7 August 2015 / Published: 14 August 2015

\begin{abstract}
Hypertrophic differentiation of chondrocytes is a main barrier in application of mesenchymal stem cells (MSCs) for cartilage repair. In addition, hypertrophy occurs occasionally in osteoarthritis (OA). Here we provide a comprehensive review on recent literature describing signal pathways in the hypertrophy of MSCs-derived in vitro differentiated chondrocytes and chondrocytes, with an emphasis on the crosstalk between these pathways. Insight into the exact regulation of hypertrophy by the signaling network is necessary for the efficient application of MSCs for articular cartilage repair and for developing novel strategies for curing OA. We focus on articles describing the role of the main signaling pathways in regulating chondrocyte hypertrophy-like changes. Most studies report hypertrophic differentiation in chondrogenesis of MSCs, in both human OA and experimental OA. Chondrocyte hypertrophy is not under the strict control of a single pathway but appears to be regulated by an intricately regulated network of multiple signaling pathways, such as WNT, Bone morphogenetic protein (BMP)/Transforming growth factor- $\beta$ (TGF $\beta$ ), Parathyroid hormone-related peptide (PTHrP), Indian hedgehog (IHH), Fibroblast growth factor (FGF), Insulin like growth factor (IGF) and Hypoxia-inducible factor (HIF). This comprehensive review describes how this intricate signaling network influences tissue-engineering applications of MSCs in articular cartilage (AC) repair, and improves understanding of the disease stages and cellular responses within an OA articular joint.
\end{abstract}


Keywords: chondrocytes; articular cartilage; signaling; signal crosstalk; hypertrophy; review; osteoarthritis; mesenchymal stem cells; chondrogenesis

\section{Introduction}

Osteoarthritis (OA) is a multifactorial complex and chronic disease characterized by progressive degradation of joint cartilage. The underlying molecular mechanisms involved in the pathogenesis and progression of OA are still largely unknown, and currently no disease-modifying therapy is available for OA.

In cell-based cartilage regeneration therapies, the use of mesenchymal stem cells (MSCs) has shown promising results. Evidence showed that MSCs can be differentiated into chondrocytes (marked by Sex determining region Y box 9 (SOX9); Aggrecan (ACAN); Collagen type II (Col2A1)) after a condensation state (marked by Cyclic adenosine monophosphate (cAMP), Transforming growth factor- $\beta$ (TGF $\beta$ ), Fibronectin, Neural cell adhesion molecule (N-CAM) and N-cadherin) in vivo and in vitro [1-3] (Figure 1a). However, in the application of human MSCs for cartilage repair in vivo, hypertrophic differentiation towards the osteogenic lineage is observed. Prevention of hypertrophy is becoming increasingly important for clinical application of MSCs in cartilage tissue engineering [1,4]. Interestingly, recent data indicate that the healthy chondrocyte phenotype switches toward a hypertrophic phenotype in degenerated cartilage [4-6]. Phenomena such as proliferation of chondrocytes, hypertrophic differentiation of chondrocytes, remodeling and mineralization of the extracellular matrix (ECM), invasion of blood vessels and apoptotic death of chondrocytes correspondingly also occur during OA [7]. In addition, transgenic mouse models have shown that deregulated hypertrophic differentiation of articular chondrocytes may be a driving factor in the onset and progression of OA [4]. Therefore, control of hypertrophic differentiation can be exploited as an effective strategy for cartilage repair, and used in bone regeneration, where hypertrophic cartilage could act as a template for endochondral bone formation [1]. However, the exact molecular mechanism underlying hypertrophic differentiation is not understood. Despite numerous studies about the function of single signaling pathways in hypertrophy, studies which explore comprehensive signaling pathways in hypertrophic differentiation of MSCs and chondrocytes have not been published in recent years. Here we discuss how signaling pathways are involved in hypertrophy of MSCs and chondrocytes, how these signaling pathways interplay, and how signal factors changed in OA disease.

\subsection{Hypertrophy in Chondrogenesis of MSCs in Vitro}

MSCs are promising candidate cells for cartilage tissue engineering, as they are present in large quantities in adipose tissue, bone marrow, synovium and cartilage [8] and can be expanded for a number of passages without losing their ability to undergo chondrogenic differentiation. Unfortunately, the phenotype of MSCs in cartilage repair is unstable [9,10]. The expression of cartilage hypertrophy markers (e.g., collagen type X) by MSCs undergoing chondrogenesis, raises concern for a tissue engineering application of MSCs, since chondrocyte hypertrophy in neocartilage could ultimately lead to apoptosis and ossification [11]. 


\subsection{Hypertrophy in Articular Chondrocytes during OA Progression}

Studies have shown that the development of OA may be caused by activation of hypertrophic differentiation of articular chondrocytes [12]. As Figure 1 shows, during hypertrophic differentiation of chondrocytes in OA, chondrocytes lose the stable phenotype and the expression of Runt-related transcription factor 2 (RUNX2), Collagen type X, Matrix metalloproteinase 13 (MMP13), Indian hedgehog (IHH) and Alkaline phosphatase (ALPL) is detected [13]. Healthy articular cartilage (AC) is a stable tissue that has the potential to resist hypertrophic differentiation and maintain the normal phenotype through an unknown mechanism [14]. The interplay of multiple signaling pathways regulates the fate of chondrocytes, i.e., to remain within cartilage or to undergo hypertrophic differentiation.

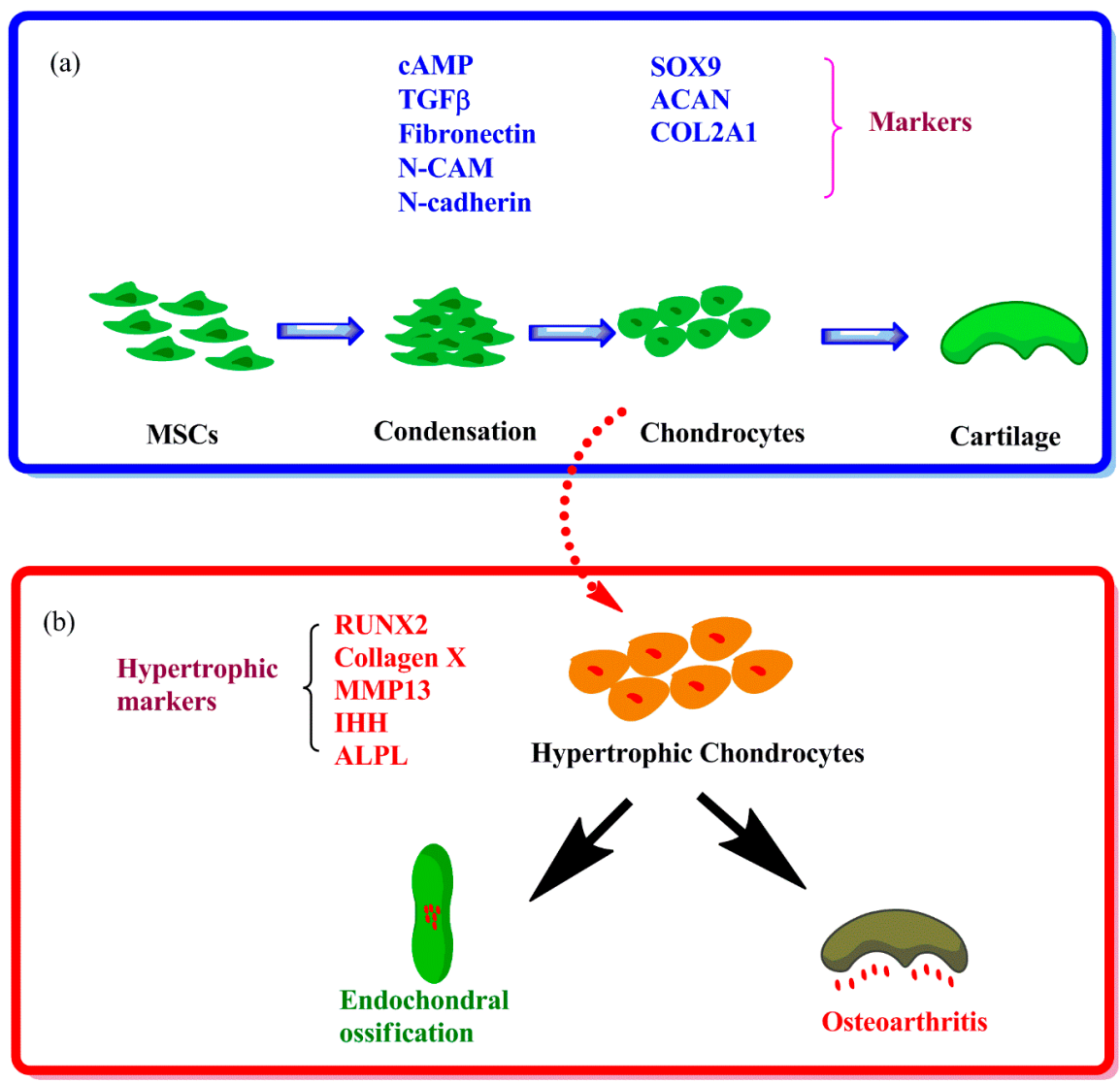

Figure 1. Chondrogenesis of MSCs and hypertrophic differentiation. (a) Chondrogenesis is initiated by the condensation of MSCs, and cell-cell contact. The expression of cAMP, TGF $\beta$, Fibronectin, N-CAM and N-cadherin is involved in this process and these factors are necessary for chondrogenic induction, marked by the expression of chondrogenic genes: SOX9, ACAN, COL2A1. Mature chondrocytes begin secreting cartilage matrix primarily consisting of collagen II and GAGs, which are the main components of cartilage; (b) Chondrocytes from in vitro chondrogenesis of MSCs or in vivo cartilage could undergo hypertrophic differentiation, which is characterized by an increase in cell volume and the expression of hypertrophic markers (RUNX2, Collagen X, MMP13, IHH and ALPL). In vivo, physiological endochondral ossification and pathological osteoarthritis could be initiated after remodeling, mineralization of the extracellular matrix, and apoptotic death of chondrocytes. 
(a) Normal Chondrocyte

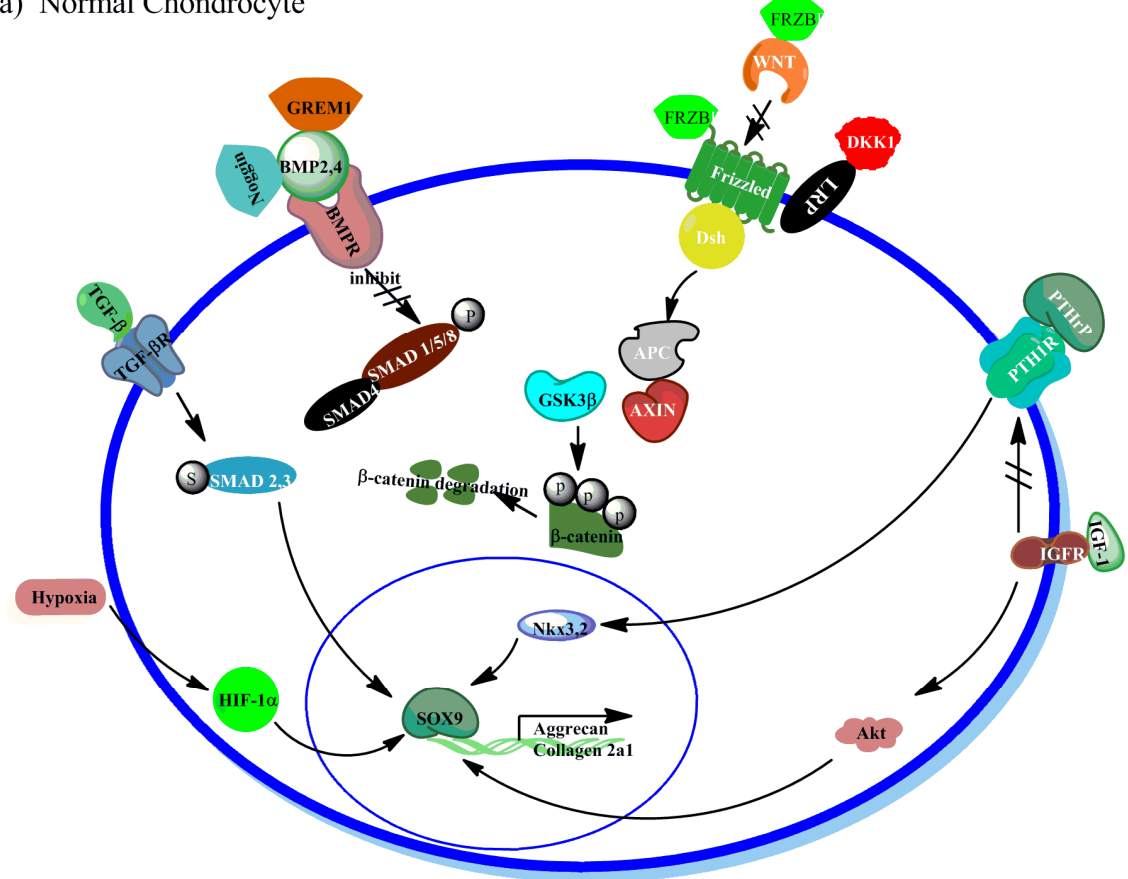

(b) Hypertrophic Chondrocyte

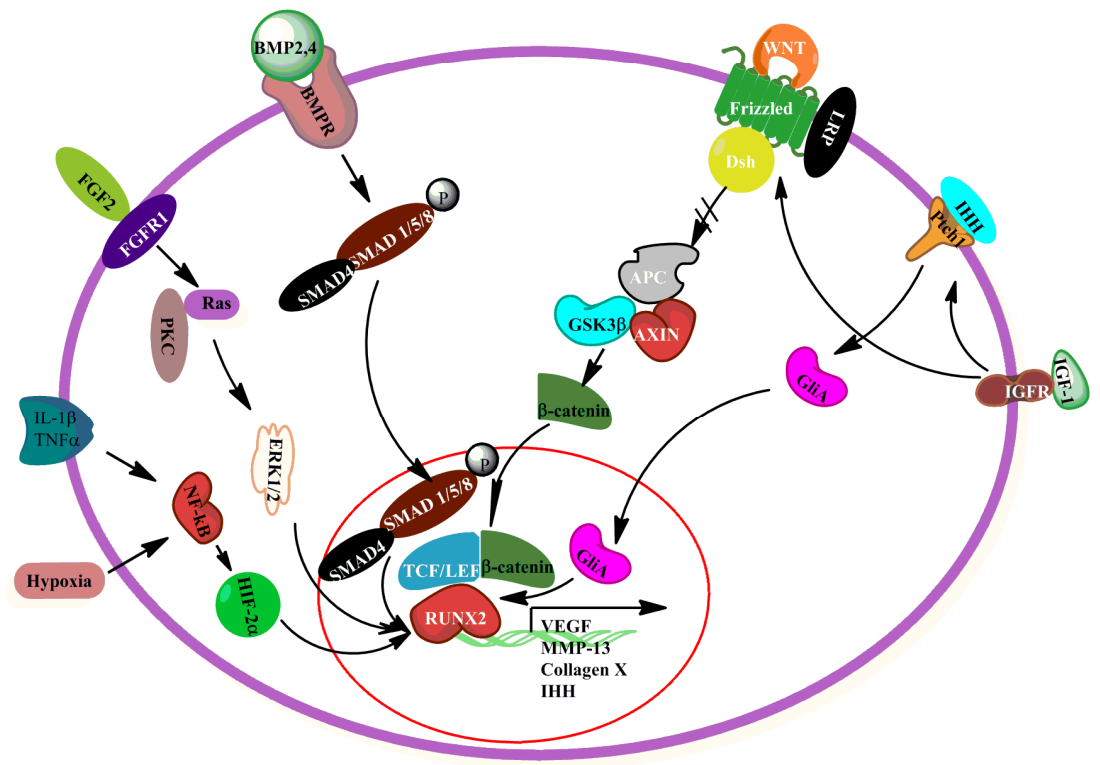

Figure 2. Signal pathways of chondrocyte hypertrophy. (a) In normal chondrocytes, signal pathways like WNT, BMP, IHH, etc. are regulated by their antagonists (DKK1 and FRZB for WNT, GREM1 for BMP) or other signal factors to get a fine balance to maintain the chondrocyte normal phenotype. The most important transcription factor regulating chondrocytes is SOX9, which is responsible for the expression of main chondrocyte makers including collagen type II and aggrecan. Striked through arrows indicate that the signaling pathway is inhibited by its antagonists; (b) In hypertrophic chondrocytes, signal pathways, such as WNT, BMP, IHH, etc. are deregulated by their inhibitors or other signal factors, which consequently leads to overexpression of these pathways. Subsequently, the effects of cascade pathways result in activating the transcription factor RUNX2, which regulates the transcription of hypertrophic markers like collagen X, MMP-13, VEGF and IHH. 


\section{Signaling Pathways in Hypertrophy}

Multiple signaling pathways have been involved in regulation of hypertrophy-like changes in chondrogenesis of MSCs and chondrocytes. Based on recent literature, the most important related pathways are WNT, Bone morphogenetic protein (BMP)/TGF $\beta$, Parathyroid hormone-related peptide (PTHrP), IHH, Fibroblast growth factor (FGF), Insulin like growth factor (IGF) and Hypoxia-inducible factor (HIF) signaling pathways [15], Figure 2. In each single pathway, several distinct subtypes are involved in the regulation of chondrocyte differentiation and hypertrophy, Table 1.

Table 1. The subtypes involved in multiple signal pathways (WNT, BMP/TGF $\beta$, PTHrP, IHH, FGF, IGF and HIF) and their main functions in the regulation of chondrocyte differentiation and hypertrophy.

\begin{tabular}{ccc}
\hline Signal & Subtypes & Main Functions \\
\hline & WNT3a & Promotes chondrogenic differentiation; delays chondrocyte hypertrophy \\
WNT4 & Blocks chondrogenic differentiation; promotes chondrocyte hypertrophy \\
WNT & WNT5a & Promotes chondrogenic differentiation; delays chondrocyte hypertrophy \\
& WNT5b & Promotes chondrogenic differentiation; delays chondrocyte hypertrophy \\
WNT8 & Blocks chondrogenic differentiation; promotes chondrocyte hypertrophy \\
& WNT9a & Blocks both chondrogenic differentiation and chondrocyte hypertrophy \\
& WNT11 & Promotes chondrogenic differentiation; stimulates RUNX2 and IHH expression \\
WNT16 & Upregulation is accompanied by the downregulation of FRZB
\end{tabular}

\subsection{WNT Signaling}

WNT signaling pathways are highly evolutionarily conserved pathways with crucial roles in embryonic development, patterning, tissue homeostasis, growth, as well as in the onset and progression of a variety of diseases [16]. There are three distinct intracellular signaling cascades well known so far: the canonical WNT/ $\beta$-catenin pathway, the c-Jun N-terminal kinase (JNK) pathway, and the WNT/Ca2 ${ }^{+}$ 
pathway [17]. The canonical WNT/ $\beta$-catenin pathway is the most-elucidated pathway, mediated by $\beta$-catenin accumulation in nucleus, having strong correlation with chondrocyte hypertrophy. As shown in Figure 2b, in most cases, the presence of WNTs that bind to the WNT receptor Frizzled, results in formation complex of Adenomatous polyposis coli protein (APC), Glycogen synthase kinase $3 \beta$ (GSK3 $\beta$ ) and Axis inhibitor (AXIN), which leads to the release of $\beta$-catenin from the complex, followed by $\beta$-catenin accumulating in the cytoplasm, and then translocation into the nucleus. There $\beta$-catenin forms a complex with $\mathrm{T}$ cell-specific factor (TCF)/lymphoid enhancer binding protein (LEF) transcription factors to activate the transcription of target genes [17]. However, in the absence of a WNT ligand, $\beta$-catenin is phosphorylated by the destruction complex and subsequently ubiquitinylated and targeted for proteasomal degradation.

Numerous studies have revealed a central role of WNT signaling in cartilage homeostasis. In cartilage, moderate activity of WNT is essential for chondrocyte proliferation and maintenance of their typical characteristics [18], but excessive activity increases chondrocyte hypertrophy and expression of cartilage degrading metalloproteinases [19]. For example, the conditional activation of the $\beta$-catenin gene in articular chondrocytes in adult mice leads to premature chondrocyte differentiation with collagen type $X$ expression and the development of an OA-like phenotype [20]. However, ablation of $\beta$-catenin in the superficial zone of articular cartilage also strongly increases the expression of aggrecan and collagen type X [18]. SOX9 is the master transcription factor and thus a typical marker of chondrocytes, while RUNX2 usually is expressed highly in hypertrophic chondrocytes. This hypertrophy may be induced by the LEF/TCF/ $\beta$-catenin complex promoting RUNX2 expression in the redundant WNT signal pathway [21]. Much evidence has shown that the switch between SOX9 and RUNX2 expression determines the progression of mature chondrocytes into hypertrophy in response to canonical WNT signaling [17,22-24].

There are several types of WNT ligands, which play different roles in the chondrogenic differentiation and cartilage development. Experiments using retroviral misexpression in vivo and overexpression methods in vitro suggest distinct roles of different WNTs in the control of chondrogenic differentiation and hypertrophy. WNT4 and WNT8 block chondrogenic differentiation but promote hypertrophy [25,26]. WNT9a blocks both chondrogenic differentiation and hypertrophy [27]. WNT3a and WNT5b promote chondrogenic differentiation but delay hypertrophy [26]. The overexpression of WNT11 in MSCs during chondrogenic differentiation promotes chondrogenesis and stimulates RUNX2 and IHH expression [28]. WNT16 transient expression was found associated with the activation of the canonical WNT pathway, and was present in the early phases of osteoarthritis, its upregulation was accompanied by the downregulation of the secreted WNT inhibitor Frizzled-related protein (FRZB) [29]. WNT5a exhibit dual functions during chondrogenesis of MSCs. At early stages, WNT5a induces chondrogenesis and hypertrophy through intracellular calcium release via G-protein coupled receptor (GPCR) activation [1]. At later stages, it can act as an inhibitor of hypertrophy by activating the phosphoinositide 3-kinase (PI3K)/protein kinase $\mathrm{B}$ (PKB or Akt)-dependent pathway, which in-turn activates nuclear factor $\kappa$-light chain-enhancer of activated B cells (NF- $\kappa \mathrm{B})$, an inhibitor of RUNX2 [30].

Interestingly, the expression of hypertrophy-related markers in chondrogenesis of MSCs is decreased in the presence of Dickkopf (DKK1), which acts as WNT signaling inhibitor (antagonist) by binding to low density lipoprotein receptor related protein (LRP5/6) through cartilage protective mechanisms [4]. Actually, DKK1, FRZB and Gremlin 1 (GREM1) are regarded as natural brakes on hypertrophic 
differentiation of articular cartilage [4]. Our studies also found increased hypertrophic differentiation and mineralization and decreased expression of chondrocyte markers in the absence of the WNT inhibitors DKK1 and FRZB during chondrogenesis of hMSCs. In MSC pellet cultures, the inhibition of canonical WNT by DKK1 and FRZB increased the expression of collagen II and aggrecan, but did not affect collagen X expression [25,31,32]. However, the reduction of WNT antagonist secreted frizzled related protein 1 (Sfrp1) in MSCs correlated with an increased amount of cytoplasmic $\beta$-catenin and an up-regulation of RUNX2 [33].

\subsection{Bone Morphogenetic Protein (BMP)/Transforming Growth Factor- $\beta$ (TGF $\beta$ ) Signaling}

\subsubsection{BMP Signaling}

BMPs are multi-functional cytokines that belong to the transforming growth factor- $\beta$ (TGF- $\beta$ ) superfamily. BMP signaling is mediated primarily through the canonical BMP-Smad pathway in chondrocytes [34]. The pathway will be activated when BMPs bind to receptors BMPR-I and II, which phosphorylate Sma and Mad related proteins (Smad) 1, Smad5, and Smad8 (R-Smads). The R-Smads form complexes with Smad4 and translocate into the nucleus, where they bind to regulatory regions of target genes to regulate their expression [35]. BMP has multiple roles during embryonic skeletal development, in addition to mesenchymal condensation and chondrogenic differentiation of MSCs, BMPs induce early cartilage formation [36] and are crucial local factors for chondrocyte proliferation and maturation in endochondral ossification [37,38].

Although BMPs have a protective effect in articular cartilage, they are also involved in chondrocyte hypertrophy and matrix degradation [39-42]. It was reported that the BMP signaling pathway was primarily activated during fracture healing via endochondral ossification and was detected in hypertrophic chondrocytes [43]. Steinert et al. showed that BMP2 and BMP4 induce hypertrophy during the chondrogenic differentiation of human MSC in vitro [37]. In another study, BMP2 was found to induce chondrocyte hypertrophy during chondrogenesis of progenitor cells ATDC5, whereas BMP-7 appeared to increase or maintain chondrogenic potential and prevent chondrocyte hypertrophy [44]. In vivo studies showed that overexpression of BMP4 in cartilage of transgenic mice resulted in an increased hypertrophic zone, indicating increased differentiation of hypertrophic chondrocytes [45]. As the BMPs also played role in the skeletal development, it may be that BMPs drive the chondrocytes to form bone after ossification, rather than to remain as articular chondrocytes [46]. Therefore, BMPs can be protective for articular cartilage but may have harmful effects on AC by inducing chondrocyte terminal differentiation and contributing to OA progression [31]. Our previous study has shown that addition of GREM1, the inhibitor of BMP signaling was able to slow down the hypertrophic differentiation and decrease the mineralization in the process of chondrogenesis of hMSCs [4]. In addition, another BMP inhibitor, Noggin, can block thyroid-induced hypertrophy by inhibiting BMP4 during MSC chondrogenesis [47].

\subsubsection{TGF- $\beta$ Signaling}

TGF $\beta$ is a potent inducer of chondrogenesis in vitro $[48,49]$. During chondrogenesis of MSCs, TGF $\beta$ is the main initiator of MSC condensation. After aggregation, TGF $\beta$ signaling further stimulates 
chondrocyte proliferation while it inhibits chondrocyte hypertrophy and maturation [50-55]. Conversely, the activation of the Smad1/5/8 pathway is able to stimulate hypertrophic differentiation with the consequent expression of the hypertrophic markers collagen X, MMP13 and ALPL during chondrogenesis of MSCs [56]. Although TGF $\beta$ is clearly crucial in inhibiting chondrocyte hypertrophy during early phases of mesenchymal condensation and chondrocyte proliferation, its addition to chondrocyte differentiation medium in pellet cultures of MSCs was not sufficient to suppress the onset of hypertrophy [9-11].

Most recently, several lines of evidence have suggested that the TGF $\beta /$ Smad pathway played a critical role in the regulation of articular chondrocytes hypertrophy and maturation during OA development [57-59]. Zuscik and colleagues have shown that treatment of articular chondrocytes with 5-azacytidine (5azaC), an anti-tumor agent that functions by blocking DNA methylation, resulted in a shift of regulatory dominance from maturation suppression via TGF $\beta$ signaling to maturation acceleration by BMP-2 signaling, which confirms that a shift in signaling dominance from TGF $\beta$ to BMP is sufficient to induce AC maturation [60]. This study also raised the possibility that a similar shift in signaling dominance occurs when these cells progresses inappropriately, such as in osteoarthritis, where the balance between TGF $\beta$ and BMP signaling pathways may be broken. It has been suggested that TGF $\beta$ inhibits terminal hypertrophic differentiation of chondrocyte and maintains normal articular cartilage through Smad2/3 signals $[58,61]$. The Smad3 pathway can be activated by TGF- $\beta$ directly to stabilize the Sox9 transcription complex and inhibits RUNX2 expression through epigenetic regulation [62,63]. Homozygous mutant mice of targeted disruption of Smad3- exon 8 developed degenerative joint disease resembling human OA, characterized by progressive loss of articular cartilage, and abnormally increased numbers of collagen type X expressing chondrocytes in synovial joints [58]. However, TGF $\beta 1$ administration has been shown to redirect expanded human articular chondrocytes towards hypertrophy [64]. Moreover, TGF $\beta$ can induce synovial lining cells to produce inflammatory factors, such as IL1 $\beta$ and TNF $\alpha$, which further stimulates articular chondrocyte terminal hypertrophy, depositing collagen type $\mathrm{X}$ instead of collagen type II and aggrecan The TGF- $\beta$ superfamily and its downstream phosphorylation of Smads were reported to exhibit both stimulatory and inhibitory effects on chondrocyte hypertrophy [65].

\subsection{The Crosstalk between BMP/TGF $\beta$ and WNT Signaling in Regulating Hypertrophy}

$\beta$-catenin crosstalk with TGF $\beta$ was reported in hypertrophy regulation in MSCs [66]. In the process of TGF $\beta$-induced chondrogenesis of MSCs, temporal activation of $\beta$-catenin led to enhanced chondrogenic induction, further developed into hypertrophy and mineralization phenotype in vivo. However, the continuous co-activation of two signaling pathways resulted in hypertrophy inhibition, characterized by the suppressed expression of collagen type X, RUNX2, and ALPL, and did not lead to ossified tissue in vivo [66].

It was demonstrated that the crosstalk between WNT and BMP plays key roles in regulating chondrocyte activity in pathogenesis of osteoarthritis, which may be cell type-specific [67]. Papathanasiou and colleagues reported the function and crosstalk between BMP2 and canonical WNT/ $\beta$-catenin signaling in regulating chondrocyte hypertrophy and matrix metalloproteinase (MMP)/aggrecanolytic ADAMTS (a disintegrin like and metalloproteinase with thrombospondin type I motif) synthesis in 
OA [68]. In this study, they showed human end-stage OA chondrocytes can produce BMP2 and BMP4. Interestingly, only BMP2, but not BMP4, can drive the expression of low-density lipoprotein receptor 5 (LRP5), which is one of most important co-receptors for WNT signaling that leads to $\beta$-catenin stabilization, accumulation, nuclear translocation, and activation of target genes. It can be concluded that the BMP-2-induced WNT/ $\beta$-catenin signaling pathway activation through LRP-5 induces chondrocyte catabolic action and hypertrophy [68].

This report adds to the accumulating evidence that increased or excessive activation of canonical WNT signaling in chondrocytes is detrimental and contributes to OA cartilage degradation. Recently, studies from our group also indicated that the natural WNT and BMP antagonists DKK1, FRZB and GREM1 inhibit hypertrophic differentiation of hMSCs during chondrogenesis by blocking WNT and BMP pathways [4]. Therefore therapeutic approaches to block or suppress canonical WNT and BMP2 pathways using their natural antagonists may protect cartilage damage in end-stage OA.

\subsection{Parathyroid Hormone-Related Peptide (PTHrP)/Indian Hedgehog (IHH) Signaling}

PTHrP is a member of the parathyroid hormone (PTH) family that blocks hypertrophy by stimulating NK3 homeobox 2 (Nkx3.2) [69] and preventing RUNX2 expression [70]. Huang supposed SOX9 is a target of PTHrP signaling in the growth plate and that the increased activity of SOX9 might mediate the effect of PTHrP in maintaining the cells as non-hypertrophic chondrocytes [71]. IHH is an important factor involved in endochondral ossification and expressed in prehypertrophic chondrocytes [72]. In IHH knockout mice, the proliferation and hypertrophy of chondrocytes are significantly reduced [73]. Evidence has shown that IHH can positively regulate the transcription and expression of collagen type $\mathrm{X}$ via Runx2/Smad interactions through downstream transcription factors GLI-Kruppel family members (Gli) 1/2 [74]. Both IHH and PTHrP signaling play crucial roles in regulating the onset of chondrocyte hypertrophy. Vortkamp and colleagues [75] found that IHH stimulated proliferating chondrocytes to produce PTHrP, which in turn accelerated the proliferation of periarticular cells and prevented the onset of chondrocyte hypertrophy, thereby keeping chondrocytes in a proliferating state. This negative feedback loop regulates the balance between proliferation and maturation of chondrocytes, ensuring orderly bone formation [75]. On the other hand, resting chondrocytes at the ends of long bones secrete PTHrP, subsequently suppressing IHH production in the proliferating zone. Chondrocytes outside of this paracrine signaling range produce IHH and undergo hypertrophy [1]. PTHrP forms a feedback loop with IHH to regulate the proliferation and onset of hypertrophic differentiation [76-78]. During endochondral bone formation, PTHrP-dependent IHH signaling inhibiting chondrocyte hypertrophy is dominant, thereby obscuring the promoting effect of PTHrP-independent IHH signaling. Other researchers reported that IHH can also function independently of PTHrP to promote chondrocyte hypertrophy [79]. In PTHrP knockout mice, the absence of PTHrP caused diminished chondrocytes and accelerated hypertrophic differentiation, and led to premature mineralization of extracellular matrix and apoptosis $[75,80]$. However, targeted overexpression of PTHrP under the control of the cartilage-specific collagen type II promoter resulted in the opposite effect of chondrodysplasia through delay of the terminal differentiation of chondrocytes, inhibition of apoptosis and disruption of endochondral ossification [81]. A co-culture model from Jiang and colleagues [82] demonstrated that in healthy articular cartilage PTHrP, secreted by chondrocytes from surface layers, inhibits the hypertrophic potential of chondrocytes residing in 
the deep layer so as to maintain the homeostasis of articular cartilage, but the effect was not confirmed in vivo. In another cell study, it was demonstrated that PTHrP from human articular chondrocytes inhibits hypertrophy of MSCs during chondrogenesis in co-culture, and intermittent supplementation of PTHrP also improves chondrogenesis of MSCs and reduces the hypertrophy [83,84]. A similar phenomenon was observed in MSCs pellet studies, it was shown that PTHrP treatment leads to suppression of hypertrophy but also down-regulates collagen II [49]. However, when cultured under hypertrophy-enhancing conditions, PTHrP could not diminish the induced enhancement of hypertrophy in the MSC pellets [85]. However, other researchers observed a selective hypertrophic inhibition upon PTHrP treatment with stable or even up-regulated expression of collagen II [86,87]. This discrepancy might be linked to the existence of both PTHrP receptor 1 (PTH1R)-dependent and PTH1R-independent pathways [1]. PTH1R knockout mice showed accelerated hypertrophy and were unaffected by treatment with PTHrP, indicating that the inhibition on hypertrophy is dependent on PTH1R receptor binding [88]. The choice of the PTHrP isoform has further been shown to affect the suppressive action on hypertrophy, with isoform 1-34 being the most effective in promotion of chondrogenesis as well as inhibition of hypertrophy [89].

Cell studies have shown that FGF2 combined with PTHrP inhibited the TGF $\beta$ responsive COL2A1 and COL10A1 expression and ALPL induction. However, calcification of implanted pellets was not prevented by PTHrP in vivo [49]. In another study, the combined delivery of TGF- $\beta 3$ and PTHrP in nude mice reduced calcification [90]. In addition, the canonical Wnt pathway is known to promote chondrocyte hypertrophy via inhibition of the PTHrP signaling activity [91]. Therefore, PTHrP represses hypertrophic cartilage differentiation whereas WNT and IHH promote hypertrophy of chondrocytes. Hence, the fine balance of the crosstalk between signal pathways is a requirement for the normal phenotype of chondrocytes.

\subsection{Fibroblast Growth Factor (FGF) Signaling}

FGF signaling plays a critical role in controlling chondrocyte differentiation [92]. Specifically, four members of the fibroblast FGF family, FGF2, FGF8, FGF9 and FGF18, have been implicated as contributing factors in cartilage homeostasis [92-96]. FGF2 has been shown to be expressed in proliferating and prehypertrophic chondrocytes, periosteal cells and osteoblasts [97]. In human articular chondrocytes, the binding of FGF2 to FGFR1 activates Ras and Protein kinase C delta (PKC $\delta$ ), which transfer the signals into the nucleus to positively regulate the expression of RUNX2 by the Raf-MEK1/2-ERK1/2 cascade [98]. Under experimental OA conditions, FGF8 has been identified as a catabolic mediator with a pathological role in rat and rabbit articular cartilage [99]. However, little is known about the precise biological function of FGF8 on human adult articular cartilage. In developing stylopod elements, FGF9 promotes chondrocyte hypertrophy at early stages and regulates vascularization of the growth plate and osteogenesis at later stages of skeletal development. Fgf $9^{-/}$mice have normal limb bud development and mesenchymal condensations, but show decreased chondrocyte proliferation in stylopod elements, delayed initiation of chondrocyte hypertrophy and abnormal osteogenesis in skeletal vascularization [95]. In the early stage of cartilage development, FGF18 is expressed in the perichondrium and joint spaces to promote chondrocyte proliferation and differentiation. In Fgf $18^{-/-}$mice, the phenomenon of delayed mineralization was observed, which was found to be closely associated with delayed initiation of chondrocyte hypertrophy, decreased chondrogenesis 
proliferation of early stages, delayed skeletal vascularization and delayed osteoclast and osteoblast recruitment to the growth plate [100]. Further studies have shown that FGF18 is necessary to induce VEGF expression by signaling to FGFR 1 and 2 in hypertrophic chondrocytes [100]. The FGF receptor 3 (FGFR3) is a tyrosine kinase receptor, expressed in proliferating chondrocytes and early hypertrophic chondrocytes in the growth plate. Both FGF9 and FGF18 are the major ligands of FGFR3 in the growth plate [101]. Recently, Shung and coworkers found that FGFR3 expression increases the expression of SOX9 and decreases $\beta$-catenin levels in cultured mesenchymal cells [102].

The interplay of WNT and FGF signaling is important to determine the fate of MSCs and their subsequent differentiation. FGFR1 appears to act downstream of the $\beta$-catenin pathway and serves as a key determinant in the lineage decision of skeletal precursors [103]. Hypertrophic maturation of chondrocytes is highly regulated by the interplay of the FGF, IHH, BMP, and WNT signaling pathways. More specifically, FGF signaling accelerates the speed of terminal hypertrophic differentiation, and acts in an antagonistic relationship with IHH expression [104]. Another study suggests that the FGF and BMP pathways collaborate to promote aspects of hypertrophic chondrocyte maturation [105]. However, cartilage of mice carrying a targeted deletion of Fgfr3 is characterized by increased regions of proliferating and hypertrophic chondrocytes [106]. A study from Weiss and colleagues also showed that FGF2, together with PTHrP, may inhibit chondrocyte hypertrophic differentiation and is therefore necessary to obtain stable chondrocytes [49].

\subsection{Insulin Like Growth Factor (IGF) Signaling}

IGF-1 has been identified as an important growth factor for skeletal development by promoting chondrocyte proliferation and maturation, while inhibiting apoptosis to form bones with appropriate size and strength. IGF-1 transmits signals via the type 1 IGF-1 receptor (IGF1R), which is expressed in the proliferating and prehypertrophic zone chondrocytes of growth plates [107]. Evidence shows that IGF-1 stimulates growth plate chondrocytes at all stages of differentiation [108]. High level of IGF-1 was detected in osteoarthritic human articular cartilage [109]. The local infusion of IGF-1 in rabbit tibial growth plate increased the numbers of both proliferative and hypertrophic chondrocytes and promoted hyperplasia of bony trabeculae within the epiphysis [110]. It has been shown that IGF-1 stimulates the chondrogenic differentiation of MSCs into chondrocytes, and into pre-hypertrophic and hypertrophic chondrocytes [111]. Recombinant adeno-associated virus (rAAV)-mediated IGF-I overexpression delayed terminal differentiation and hypertrophy in the newly formed cartilage, which may be due to contrasting effects upon the osteogenic expression of RUNX2 and $\beta$-catenin [112]. Another study demonstrates that IGF-1 enhances chondrocyte hypertrophy by insulin-like actions, and that terminal hypertrophic chondrocytes are reduced in Igf1 null mice [113]. Repudi's study showed that WNT induced secreted protein 3 (WISP3) inhibits IGF-1 induced collagen X induction, reactive oxygen species (ROS) accumulation and ALPL activity, all of which are associated with the induction of chondrocyte hypertrophy [114]. In addition, Mushtaq also found that IGF-1 stimulated chondrocyte hypertrophy and reversed the growth-inhibitory dexamethasone effects in mouse metatarsal [115]. However, evidence shows that chick embryo chondrocytes maintained their normal phenotype and were prevented to undergo hypertrophic differentiation in the presence of IGF-1 [116]. Clearly, the IGF-I 
mediated improvement in growth was performed by altering the balance between proliferating and hypertrophic chondrocytes.

IGF-1 signaling also is involved in the interaction between the thyroid hormone and the $\mathrm{WNT} / \beta$-catenin signaling pathways in regulating growth plate chondrocyte proliferation and differentiation. Evidence showed that IGF-1 and the IGF-1 receptor (IGF1R) stimulate Wnt-4 expression and $\beta$-catenin activation in growth plate chondrocytes. Chondrocyte proliferation and terminal differentiation induced by IGF-1/IGF1R can be partially inhibited by the Wnt antagonists FRZB and DKK1 [117]. The IGF-1/IGF1R signaling and IGF-1 dependent PI3K/Akt/GSK-3 $\beta$ signaling can be activated by triiodothyronine $\left(\mathrm{T}_{3}\right)$ in the growth plate, and the chondrocytes undergo proliferation and differentiate to prehypertrophy. It seems that chondrocyte proliferation may be triggered by the IGF-1/IGF1R-mediated PI3K/Akt/GSK3 $\beta$ pathway, while cell hypertrophy is likely due to activation of Wnt/ $\beta$-catenin signaling, which is at least in part initiated by IGF-1 signaling or the IGF-1-activated PI3K/Akt signaling pathway [117]. The fact that $\mathrm{IHH}$ expression was reduced in $\mathrm{Igf1}^{-/-}$mice long bones, whereas expression of PTHrP was increased, suggested that IGF-1 signaling is also required to maintain the IHH-PTHrP loop during skeletogenesis [118].

\subsection{Hypoxia-Inducible Factor (HIF) Signaling}

Healthy articular cartilage is a typical avascular tissue, and chondrocytes are able to survive in low oxygen environments [119]. Hypoxia is considered to be a positive influence on the healthy chondrocyte phenotype and cartilage matrix formation. A recent study from our group has shown that the articular cartilage-enriched gene transcripts of GREM1, FRZB, and DKK1, which are established inhibitors of hypertrophic differentiation, were robustly increased in chondrogenic hMSCs pellets under hypoxic conditions, whereas under normoxia conditions these genes did not increase markedly [120]. Evidence shows that hypoxia enhances chondrogenesis and prevents terminal differentiation through a PI3K/Akt/FoxO dependent anti-apoptotic effect [121]. The hypoxic response is mainly mediated by HIF, which includes three family members, HIF-1 $\alpha,-2 \alpha,-3 \alpha$ [122], particularly HIF-1 $\alpha$ and HIF-2 $\alpha$, play an active role in chondrocyte development.

Under hypoxic conditions, the transcription factor HIF-1 $\alpha$ accumulates and activates the transcription of genes, which are involved in energy metabolism, angiogenesis, vasomotor control, apoptosis, proliferation, and matrix production. In subcutaneous stem cell implantation studies, HIF-1 $\alpha$ was shown to potentiate BMP2-induced SOX9 and cartilage formation, while inhibiting RUNX2 and endochondral ossification during ectopic bone/cartilage formation. In the fetal limb culture, HIF-1 $\alpha$ and BMP2 synergistically promoted the expansion of the proliferating chondrocyte zone and inhibited chondrocyte hypertrophy and endochondral ossification [123]. However, HIF-2 $\alpha$, encoded by Epas 1, was identified as a regulator of endochondral bone formation, and appears to be a central positive regulator of collagen $\mathrm{X}, \mathrm{MMP} 13$ and VEGF expression by enhancing promoter activities through specific binding to the hypoxia-responsive elements [124]. Inflammatory factors like IL-1 $\beta$ and TNF- $\alpha$ can increase the HIF- $2 \alpha$ expression by NF- $\mathrm{KB}$ signaling in chondrocytes [124,125]. Further experiments have shown HIF-2 $\alpha$ participates in crosstalk with the $\beta$-catenin and NF- $\mathrm{BB}$ pathways to promote chondrocyte apoptosis and endochondral ossification [126]. RUNX2 and IHH were identified as the possible transcriptional targets of HIF- $2 \alpha$ related to endochondral ossification; both of them are 
involved inthe regulation of hypertrophic differentiation of chondrocytes [124,127]. The gene corresponding to nicotinamide phosphoribosyltransferase (NAMPT) is also a direct target of HIF-2 $\alpha$, and plays an essential catabolic role in OA pathogenesis and acts as a crucial mediator of osteoarthritic cartilage destruction caused by HIF-2 $\alpha$ or destabilisation of the medial meniscus (DMM) surgery [128]. There is evidence that HIF-2 $\alpha$ causes cartilage destruction by regulating crucial catabolic genes [125] and potentiating Fas-mediated chondrocyte apoptosis [129]. However, Lafont and coworkers found that hypoxia promotes cartilage matrix synthesis specifically through HIF- $2 \alpha$ but not HIF-1 $\alpha$ mediated SOX9 induction of key cartilage genes [130]. The seemingly conflicting effects of HIF-2 $\alpha$ to chondrocyte or cartilage could be induced through different pathways and the differences in experiments performed in vivo and in vitro, which need to be clarified. The balance between HIF-1 $\alpha / \mathrm{HIF}-2 \alpha$ activities clearly contributes to the control of cartilage homeostasis.

\section{Conclusions}

Chondrocyte differentiation is regulated by multiple signal transduction pathways. Maintaining a normal chondrocyte phenotype and avoiding hypertrophy is important for cartilage repair. SOX9 and RUNX2 are two typical markers in chondrocyte development. SOX9 is expressed in chondrocytes, while RUNX2 is highly expressed in hypertrophic chondrocytes. In most cases, a hypertrophic phenotype was accompanied by high expression of RUNX2 through activation of either of the WNT, BMP, IHH, FGF and HIF signaling pathways. However, TGF $\beta$, IGF-I and PTHrP promote the proliferation of chondrocytes. Here we propose a model in which the balance of these signal pathways adjusts the state of chondrocyte proliferation or hypertrophy through the shifting between SOX9 and RUNX2 transcriptional activities. In the WNT pathway, the LEF/TCF/ $\beta$-catenin complex can promote RUNX2 expression. BMP/TGF- $\beta$ signaling has a dual role in the chondrocyte development. TGF- $\beta$ induces collagen II and SOX9 deposition through Smad2/3 phosphorylation pathway, while BMP2/4 promotes chondrocyte hypertrophy and cartilage mineralization via Smad1/5/8 phosphorylation. PTHrP represses hypertrophic cartilage differentiation whereas IHH signaling positively regulates the hypertrophic phenotype by high transcription and expression of collagen type X and RUNX2. IGF-1 signaling stimulates chondrocyte proliferation by the IGF-1/IGF1R-mediated PI3K/Akt/GSK3 $\beta$ pathway, while cell hypertrophy is likely due to activation of Wnt/ $\beta$-catenin and IHH signaling by IGF- 1 . HIF- $1 \alpha$ and HIF- $2 \alpha$ have a distinct role in the chondrocyte development. The former inhibits the RUNX2 expression, while the latter enhances the expression of collagen X, MMP13 and RUNX2 and promotes the hypertrophic differentiation of chondrocytes. The fine balance of the crosstalk between these signaling pathways is a requirement for normal chondrocyte differentiation and cartilage development.

\section{Acknowledgments}

Leilei Zhong is funded by the Dutch Arthritis Association (Reumafonds) grant number 11-1-408 to Janine N. Post and Marcel Karperien.

\section{Author Contributions}

The manuscript was initiated by Janine N. Post and Leilei Zhong, all authors wrote the manuscript. 


\section{Conflicts of Interest}

The authors declare no conflict of interest. The founding sponsors had no role in the design of the study; in the collection, analyses, or interpretation of data; in the writing of the manuscript, and in the decision to publish.

\section{Abbreviations}

MSCs: Mesenchymal stem cells; OA: Osteoarthritis; WNT: Wingless-type MMTV integration site; BMP: Bone morphogenetic protein; TGF $\beta$ : Transforming growth factor- $\beta$; PTHrP: Parathyroid hormone-related peptide; IHH: Indian hedgehog; FGF: Fibroblast growth factor; IGF: Insulin like growth factor; HIF: Hypoxia-inducible factor; AC: Articular cartilage; SOX9: Sex determining region Y box 9; ACAN: Aggrecan; Col2A1: Collagen type II; cAMP: Cyclic adenosine monophosphate; N-CAM: Neural cell adhesion molecule; ECM: extracellular matrix; RUNX2: Runt-related transcription factor 2; MMP: Matrix metalloproteinase; ALPL: Alkaline phosphatase; VEGF: Vascular endothelial growth factor; JNK: c-Jun N-terminal kinase; AXIN2: Axis inhibitor 2; APC: Adenomatous polyposis

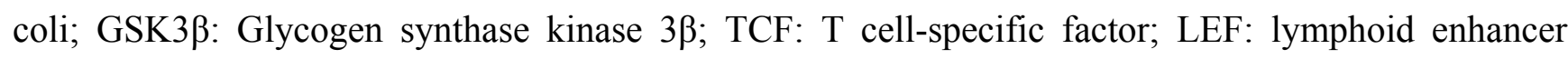
binding protein; LRP5/6: Low density lipoprotein receptor related protein 5/6; SFRP 1: WNT antagonist secreted frizzled related protein 1; GPCR: G-protein coupled receptor; PI3K; phosphoinositide 3-kinase (PI3K); PKB/Akt: protein kinase B; NF- $\mathrm{B}$ : Nuclear factor $\kappa$-light chain-enhancer of activated B cells; BMPR: BMP receptor; SMAD: Sma and Mad related proteins; ALK: Activin-like kinase; ADAMTS: A disintegrin like and metalloproteinase with thrombospondin type I motif; Nkx3.2: NK3 homeobox 2; Gli: GLI-Kruppel family members; PTH1R: PTHrP receptor 1; PKC $\delta$ : Protein kinase C delta; ERKs: extracellular-signal-regulated kinases; MEK: Mitogen-activated protein kinase kinase; FGFR3: The FGF receptor 3; IGF1R: IGF-I receptor; rAAV: Recombinant adeno-associated virus; WISP3: WNT induced secreted protein 3; ROS: Reactive oxygen species; NAMPT: Nicotinamide phosphoribosyltransferase; DMM: Medial meniscus; T3: triiodothyronine; DKK1: Dickkopf; FRZB: Frizzled-related protein; GREM1: Gremlin 1.

\section{References}

1. Studer, D.; Millan, C.; Öztürk, E.; Maniura-Weber, K.; Zenobi-Wong, M. Molecular and biophysical mechanisms regulating hypertrophic differentiation in chondrocytes and mesenchymal stem cells. Eur. Cell Mater. 2012, 24, 118-135.

2. Hall, B.K.; Miyake, T. All for one and one for all: Condensations and the initiation of skeletal development. Bioessays 2000, 22, 138-147.

3. Mrugala, D.; Dossat, N.; Ringe, J.; Delorme, B.; Coffy, A.; Bony, C.; Charbord, P.; Häupl, T.; Daures, J.P.; Noël, D.; et al. Gene expression profile of multipotent mesenchymal stromal cells: Identification of pathways common to TGF 33 /BMP2-induced chondrogenesis. Cloning Stem Cells 2009, 11, 61-76.

4. Leijten, J.C.; Emons, J.; Sticht, C.; van Gool, S.; Decker, E.; Uitterlinden, A.; Rappold, G.; Hofman, A.; Rivadeneira, F.; Scherjon, S. Gremlin 1, frizzled-related protein, and Dkk-1 are key regulators of human articular cartilage homeostasis. Arthritis Rheumatol. 2012, 64, 3302-3312. 
5. Goldring, M.B.; Marcu, K.B. Cartilage homeostasis in health and rheumatic diseases. Arthritis Res. Ther. 2009, 11, 224.

6. Fosang, A.J.; Beier, F. Emerging Frontiers in cartilage and chondrocyte biology. Best Pract. Res. Clin. Rheumatol. 2011, 25, 751-766.

7. Dreier, R. Hypertrophic differentiation of chondrocytes in osteoarthritis: The developmental aspect of degenerative joint disorders. Arthritis Res. Ther. 2010, 12, 216.

8. Williams, R.; Khan, I.M.; Richardson, K.; Nelson, L.; McCarthy, H.E.; Analbelsi, T.; Singhrao, S.K.; Dowthwaite, G.P.; Jones, R.E.; Baird, D.M.; et al. Identification and clonal characterisation of a progenitor cell sub-population in normal human articular cartilage. PLOS ONE 2010, 5, e13246.

9. Sekiya, I.; Vuoristo, J.T.; Larson, B.L.; Prockop, D.J. In vitro cartilage formation by human adult stem cells from bone marrow stroma defines the sequence of cellular and molecular events during chondrogenesis. Proc. Natl. Acad. Sci. USA 2002, 99, 4397-4402.

10. Pelttari, K.; Winter, A.; Steck, E.; Goetzke, K.; Hennig, T.; Ochs, B.G.; Aigner, T.; Richter, W. Premature induction of hypertrophy during in vitro chondrogenesis of human mesenchymal stem cells correlates with calcification and vascular invasion after ectopic transplantation in SCID mice. Arthritis Rheumatol. 2006, 54, 3254-3266.

11. Mueller, M.B.; Tuan, R.S. Functional characterization of hypertrophy in chondrogenesis of human mesenchymal stem cells. Arthritis Rheumatol. 2008, 58, 1377-1388.

12. Hunter, D.J.; Felson, D.T. Osteoarthritis. BMJ 2006. 332, 639-642.

13. Van der Kraan, P.M.; van den Berg, W.B. Chondrocyte hypertrophy and osteoarthritis: Role in initiation and progression of cartilage degeneration? Osteoarthr. Cartil. 2012, 20, 223-232.

14. Mackie, E.J.; Ahmed, Y.A.; Tatarczuch, L.; Chen, K.S.; Mirams, M. Endochondral ossification: How cartilage is converted into bone in the developing skeleton. Int. J. Biochem. Cell Biol. 2008, $40,46-62$.

15. Kronenberg, H.M. Developmental regulation of the growth plate. Nature 2003, 423, 332-336.

16. Miller, J.R. The Wnts. Genome Biol. 2002, 3, 1-15.

17. Yano, F.; Kugimiya, F.; Ohba, S.; Ikeda, T.; Chikuda, H.; Ogasawara, T.; Ogata, N.; Takato, T.; Nakamura, K.; Kawaguchi, H.; et al. The canonical Wnt signaling pathway promotes chondrocyte differentiation in a Sox9-dependent manner. Biochem. Biophys. Res. Commun. 2005, 333, 1300-1308.

18. Yasuhara, R.; Ohta, Y.; Yuasa, T.; Kondo, N.; Hoang, T.; Addya, S.; Fortina, P.; Pacifici, M.; Iwamoto, M.; Enomoto-Iwamoto, M. Roles of $\beta$-catenin signaling in phenotypic expression and proliferation of articular cartilage superficial zone cells. Lab. Investig. 2011, 91, 1739-1752.

19. Blom, A.B.; Brockbank, S.M.; van Lent, P.L.; van Beuningen, H.M.; Geurts, J.; Takahashi, N.; van der Kraan, P.M.; van de Loo, F.A.; Schreurs, B.W.; Clements, K.; et al. Involvement of the Wnt signaling pathway in experimental and human osteoarthritis: Prominent role of Wnt-induced signaling protein 1. Arthritis Rheumatol. 2009, 60, 501-512.

20. Zhu, M.; Tang, D.; Wu, Q.; Hao, S.; Chen, M.; Xie, C.; Rosier, R.N.; O’Keefe, R.J.; Zuscik, M.; Chen, D. Activation of $\beta$-catenin signaling in articular chondrocytes leads to osteoarthritis-like phenotype in adult $\beta$-catenin conditional activation mice. J. Bone Miner. Res. 2009, 24, 12-21.

21. Dong, Y.F.; Soung do, Y.; Schwarz, E.M.; O’Keefe, R.J.; Drissi, H. Wnt induction of chondrocyte hypertrophy through the Runx2 transcription factor. J. Cell. Physiol. 2006, 208, 77-86. 
22. Akiyama, H.; Lyons, J.P.; Mori-Akiyama, Y.; Yang, X.; Zhang, R.; Zhang, Z.; Deng, J.M.; Taketo, M.M.; Nakamura, T.; Behringer, R.R.; et al. Interactions between Sox 9 and $\beta$-catenin control chondrocyte differentiation. Genes Dev. 2004, 18, 1072-1087.

23. Hill, T.P.; Später, D.; Taketo, M.M.; Birchmeier, W.; Hartmann, C. Canonical Wnt/ $\beta$-catenin signaling prevents osteoblasts from differentiating into chondrocytes. Dev. Cell 2005, 8, 727-738.

24. Tamamura, Y.; Otani, T.; Kanatani, N.; Koyama, E.; Kitagaki, J.; Komori, T.; Yamada, Y.; Costantini, F.; Wakisaka, S.; Pacifici, M.; et al. Developmental regulation of Wnt/ $\beta$-catenin signals is required for growth plate assembly, cartilage integrity, and endochondral ossification. J. Biol. Chem. 2005, 280, 19185-19195.

25. Enomoto-Iwamoto, M.; Kitagaki, J.; Koyama, E.; Tamamura, Y.; Wu, C.; Kanatani, N.; Koike, T.; Okada, H.; Komori, T.; Yoneda, T.; et al. The Wnt antagonist Frzb-1 regulates chondrocyte maturation and long bone development during limb skeletogenesis. Dev. Biol. 2002, 251, 142-156.

26. Church, V.; Nohno, T.; Linker, C.; Marcelle, C.; Francis-West, P. Wnt regulation of chondrocyte differentiation. J. Cell Sci. 2002, 115, 4809-4818.

27. Hartmann, C.; Tabin, C.J. Wnt-14 plays a pivotal role in inducing synovial joint formation in the developing appendicular skeleton. Cell 2001, 104, 341-351.

28. Liu, S.; Zhang, E.; Yang, M.; Lu, L. Overexpression of Wnt11 promotes chondrogenic differentiation of bone marrow-derived mesenchymal stem cells in synergism with TGF- $\beta$. Mol. Cell. Biochem. 2014, 390, 123-131.

29. Dell'accio, F.; de Bari, C.; Eltawil, N.M.; Vanhummelen, P.; Pitzalis, C. Identification of the molecular response of articular cartilage to injury, by microarray screening: Wnt-16 expression and signaling after injury and in osteoarthritis. Arthritis Rheumatol. 2008, 58, 1410-1421.

30. Bradley, E.W.; Drissi, M.H. WNT5A regulates chondrocyte differentiation through differential use of the CaN/NFAT and IKK/NF-кB pathways. Mol. Endocrinol. 2010, 24, 1581-1593.

31. Van der Kraan, P.M.; Blaney Davidson, E.N.; van den Berg, W.B. Bone morphogenetic proteins and articular cartilage: To serve and protect or a wolf in sheep clothing's? Osteoarthr. Cartil. 2010, $18,735-741$.

32. Im, G.I.; Lee, J.M.; Kim, H.J. Wnt inhibitors enhance chondrogenesis of human mesenchymal stem cells in a long-term pellet culture. Biotechnol. Lett. 2011, 33, 1061-1068.

33. Pasold, J.; Osterberg, A.; Peters, K.; Taipaleenmäki, H.; Säämänen, A.M.; Vollmar, B.; Müller-Hilke, B. Reduced expression of Sfrp1 during chondrogenesis and in articular chondrocytes correlates with osteoarthritis in STR/ort mice. Exp. Cell Res. 2013, 319, 649-659.

34. Chan, B.Y.; Little, C.B. The interaction of canonical bone morphogenetic protein- and Wnt-signaling pathways may play an important role in regulating cartilage degradation in osteoarthritis. Arthritis Res. Ther. 2012, 14, 119.

35. Miyazawa, K.; Shinozaki, M.; Hara, T.; Furuya, T.; Miyazono, K. Two major Smad pathways in TGF- $\beta$ superfamily signalling. Genes Cells 2002, 7, 1191-1204.

36. Chen, D.; Zhao, M.; Mundy, G.R. Bone morphogenetic proteins. Growth Factors 2004, 22, 233-241.

37. Steinert, A.F.; Proffen, B.; Kunz, M.; Hendrich, C.; Ghivizzani, S.C.; Nöth, U.; Rethwilm, A.; Eulert, J.; Evans, C.H. Hypertrophy is induced during the in vitro chondrogenic differentiation of human mesenchymal stem cells by bone morphogenetic protein-2 and bone morphogenetic protein-4 gene transfer. Arthritis Res. Ther. 2009, 11, R148. 
38. Shu, B.; Zhang, M.; Xie, R.; Wang, M.; Jin, H.; Hou, W.; Tang, D.; Harris, S.E.; Mishina, Y.; O'Keefe, R.J. BMP2, but not BMP4, is crucial for chondrocyte proliferation and maturation during endochondral bone development. J. Cell Sci. 2011, 124, 3428-3440.

39. Zhang, M.; Yan, Y.; Lim, Y.B.; Tang, D.; Xie, R.; Chen, A.; Tai, P.; Harris, S.E.; Xing, L.; Qin, Y.X.; et al. BMP-2 modulates $\beta$-catenin signaling through stimulation of Lrp5 expression and inhibition of $\beta$-TrCP expression in osteoblasts. J. Cell. Biochem. 2009, 108, 896-905.

40. Retting, K.N.; Song, B.; Yoon, B.S.; Lyons, K.M. BMP canonical Smad signaling through Smad1 and Smad5 is required for endochondral bone formation. Development 2009, 136, 1093-1104.

41. Miyazono, K.; Maeda, S.; Imamura, T. Coordinate regulation of cell growth and differentiation by TGF- $\beta$ superfamily and Runx proteins. Oncogene 2004, 23, 4232-4237.

42. Leboy, P.; Grasso-Knight, G.; D’Angelo, M.; Volk, S.W.; Lian, J.V.; Drissi, H.; Stein, G.S.; Adams, S.L. Smad-Runx interactions during chondrocyte maturation. J. Bone Jt. Surg. Am. 2001, $83, \mathrm{~S} 15-\mathrm{S} 22$.

43. Yu, Y.Y.; Lieu, S.; Lu, C.; Miclau, T.; Marcucio, R.S.; Colnot, C. Immunolocalization of BMPs, BMP antagonists, receptors, and effectors during fracture repair. Bone 2010, 46, 841-851.

44. Caron, M.M.; Emans, P.J.; Cremers, A.; Surtel, D.A.; Coolsen, M.M.; van Rhijn, L.W.; Welting, T.J. Hypertrophic differentiation during chondrogenic differentiation of progenitor cells is stimulated by BMP-2 but suppressed by BMP-7. Osteoarthr. Cartil. 2013, 21, 604-613.

45. Tsumaki, N.; Nakase, T.; Miyaji, T.; Kakiuchi, M.; Kimura, T.; Ochi, T.; Yoshikawa, H. Bone morphogenetic protein signals are required for cartilage formation and differently regulate joint development during skeletogenesis. J. Bone Miner. Res. 2002, 17, 898-906.

46. Zou, L.; Zou, X.; Li, H.; Mygind, T.; Zeng, Y.; Lü, N.; Bünger, C. Molecular mechanism of osteochondroprogenitor fate determination during bone formation. Adv. Exp. Med. Biol. 2006, 585, 431-441.

47. Karl, A.; Olbrich, N.; Pfeifer, C.; Berner, A.; Zellner, J.; Kujat, R.; Angele, P.; Nerlich, M.; Mueller, M.B. Thyroid hormone-induced hypertrophy in mesenchymal stem cell chondrogenesis is mediated by bone morphogenetic protein-4. Tissue Eng. Part A 2014, 20, 178-188.

48. Barry, F.; Boynton, R.E.; Liu, B.; Murphy, J.M. Chondrogenic differentiation of mesenchymal stem cells from bone marrow: Differentiation-dependent gene expression of matrix components. Exp. Cell Res. 2001, 268, 189-200.

49. Weiss, S.; Hennig, T.; Bock, R.; Steck, E.; Richter, W. Impact of growth factors and PTHrP on early and late chondrogenic differentiation of human mesenchymal stem cells. J. Cell. Physiol. 2010, 223, 84-93.

50. Song, J.J.; Aswad, R.; Kanaan, R.A.; Rico, M.C.; Owen, T.A.; Barbe, M.F.; Safadi, F.F.; Popoff, S.N. Connective tissue growth factor (CTGF) acts as a downstream mediator of TGF- $\beta 1$ to induce mesenchymal cell condensation. J. Cell. Physiol. 2007, 210, 398-410.

51. Tuli, R.; Tuli, S.; Nandi, S.; Huang, X.; Manner, P.A.; Hozack, W.J.; Danielson, K.G.; Hall, D.J.; Tuan, R.S. Transforming growth factor- $\beta$-mediated chondrogenesis of human mesenchymal progenitor cells involves N-cadherin and mitogen-activated protein kinase and Wnt signaling cross-talk. J. Biol. Chem. 2003, 278, 41227-41236. 
52. Ballock, R.T.; Heydemann, A.; Wakefield, L.M.; Flanders, K.C.; Roberts, A.B.; Sporn, M.B. TGF- $\beta$ 1 prevents hypertrophy of epiphyseal chondrocytes: Regulation of gene expression for cartilage matrix proteins and metalloproteases. Dev. Biol. 1993, 158, 414-429.

53. Tschan, T.; Böhme, K.; Conscience-Egli, M.; Zenke, G.; Winterhalter, K.H.; Bruckner, P. Autocrine or paracrine transforming growth factor- $\beta$ modulates the phenotype of chick embryo sternal chondrocytes in serum-free agarose culture. J. Biol. Chem. 1993, 268, 5156-5161.

54. Dieudonne, S.C.; Semeins, C.M.; Goei, S.W.; Vukicevic, S.; Nulend, J.K.; Sampath, T.K.; Helder, M.; Burger, E.H. Opposite effects of osteogenic protein and transforming growth factor $\beta$ on chondrogenesis in cultured long bone rudiments. J. Bone Miner. Res. 1994, 9, 771-780.

55. Bohme, K.; Winterhalter, K.H.; Bruckner, P. Terminal differentiation of chondrocytes in culture is a spontaneous process and is arrested by transforming growth factor- $\beta 2$ and basic fibroblast growth factor in synergy. Exp. Cell Res. 1995, 216, 191-198.

56. Hellingman, C.A.; Davidson, E.N.; Koevoet, W.; Vitters, E.L.; van den Berg, W.B.; van Osch, G.J.; van der Kraan, P.M. Smad signaling determines chondrogenic differentiation of bone-marrow-derived mesenchymal stem cells: Inhibition of Smad1/5/8P prevents terminal differentiation and calcification. Tissue Eng. Part A 2011, 17, 1157-1167.

57. Shen, J.; Li, J.; Wang, B.; Jin, H.; Wang, M.; Zhang, Y.; Yang, Y.; Im, H.J.; O’Keefe, R.; Chen, D. Deletion of the transforming growth factor $\beta$ receptor type II gene in articular chondrocytes leads to a progressive osteoarthritis-like phenotype in mice. Arthritis Rheumatol. 2013, 65, 3107-3119.

58. Yang, X.; Chen, L.; Xu, X.; Li, C.; Huang, C.; Deng, C.X. TGF- $\beta /$ Smad3 signals repress chondrocyte hypertrophic differentiation and are required for maintaining articular cartilage. J. Cell Biol. 2001, 153, 35-46.

59. Wang, W.; Rigueur, D.; Lyons, K.M. TGF $\beta$ signaling in cartilage development and maintenance. Birth Defects Res. Part C Embryo Today 2014, 102, 37-51.

60. Zuscik, M.J.; Baden, J.F.; Wu, Q.; Sheu, T.J.; Schwarz, E.M.; Drissi, H.; O’Keefe, R.J.; Puzas, J.E.; Rosier, R.N. 5-azacytidine alters TGF- $\beta$ and BMP signaling and induces maturation in articular chondrocytes. J. Cell. Biochem. 2004, 92, 316-331.

61. Li, T.F.; Darowish, M.; Zuscik, M.J.; Chen, D.; Schwarz, E.M.; Rosier, R.N.; Drissi, H.; O’Keefe, R.J. Smad3-deficient chondrocytes have enhanced BMP signaling and accelerated differentiation. J. Bone Miner. Res. 2006, 21, 4-16.

62. Furumatsu, T.; Tsuda, M.; Taniguchi, N.; Tajima, Y.; Asahara, H. Smad3 induces chondrogenesis through the activation of SOX9 via CREB-binding protein/p300 recruitment. J. Biol. Chem. 2005, 280, 8343-8350.

63. Kang, J.S.; Alliston, T.; Delston, R.; Derynck, R. Repression of Runx 2 function by TGF- $\beta$ through recruitment of class II histone deacetylases by Smad3. EMBO J. 2005, 24, 2543-2555.

64. Narcisi, R.; Quarto, R.; Ulivi, V.; Muraglia, A.; Molfetta, L.; Giannoni, P. TGF $\beta-1$ administration during ex vivo expansion of human articular chondrocytes in a serum-free medium redirects the cell phenotype toward hypertrophy. J. Cell. Physiol. 2012, 227, 3282-3290.

65. Van der Kraan, P.M.; Blaney Davidson, E.N.; Blom, A.; van den Berg, W.B. TGF- $\beta$ signaling in chondrocyte terminal differentiation and osteoarthritis: Modulation and integration of signaling pathways through receptor-Smads. Osteoarthr. Cartil. 2009, 17, 1539-1545. 
66. Yang, Z.; Zou, Y.; Guo, X.M.; Tan, H.S.; Denslin, V.; Yeow, C.H.; Ren, X.F.; Liu, T.M.; Hui, J.H.; Lee, E.H. Temporal activation of $\beta$-catenin signaling in the chondrogenic process of mesenchymal stem cells affects the phenotype of the cartilage generated. Stem Cells Dev. 2012, 21, 1966-1976.

67. Itasaki, N.; Hoppler, S. Crosstalk between Wnt and bone morphogenic protein signaling: A turbulent relationship. Dev. Dyn. 2010, 239, 16-33.

68. Papathanasiou, I.; Malizos, K.N.; Tsezou, A. Bone morphogenetic protein-2-induced Wnt/ $\beta$-catenin signaling pathway activation through enhanced low-density-lipoprotein receptor-related protein 5 catabolic activity contributes to hypertrophy in osteoarthritic chondrocytes. Arthritis Res. Ther. 2012, 14, R82.

69. Provot, S.; Kempf, H.; Murtaugh, L.C.; Chung, U.I.; Kim, D.W.; Chyung, J.; Kronenberg, H.M.; Lassar, A.B. Nkx3.2/Bapx1 acts as a negative regulator of chondrocyte maturation. Development 2006, 133, 651-662.

70. Zhang, M.; Xie, R.; Hou, W.; Wang, B.; Shen, R.; Wang, X.; Wang, Q.; Zhu, T.; Jonason, J.H.; Chen, D. PTHrP prevents chondrocyte premature hypertrophy by inducing cyclin-D1-dependent Runx2 and Runx3 phosphorylation, ubiquitylation and proteasomal degradation. J. Cell Sci. 2009, $122,1382-1389$.

71. Huang, W.; Zhou, X.; Lefebvre, V.; de Crombrugghe, B. Phosphorylation of SOX9 by cyclic AMP-dependent protein kinase A enhances SOX9's ability to transactivate a Col2a1 chondrocyte-specific enhancer. Mol. Cell. Biol. 2000, 20, 4149-4158.

72. Worthley, D.L.; Churchill, M.; Compton, J.T.; Tailor, Y.; Rao, M.; Si, Y.; Levin, D.; Schwartz, M.G.; Uygur, A.; Hayakawa, Y.; et al. Gremlin 1 identifies a skeletal stem cell with bone, cartilage, and reticular stromal potential. Cell 2015, 160, 269-284.

73. Kim, E.J.; Cho, S.W.; Shin, J.O.; Lee, M.J.; Kim, K.S.; Jung, H.S. Ihh and Runx2/Runx3 signaling interact to coordinate early chondrogenesis: A mouse model. PLoS ONE 2013, 8, e55296.

74. Amano, K.; Densmore, M.; Nishimura, R.; Lanske, B. Indian hedgehog signaling regulates transcription and expression of collagen type X via Runx2/Smads interactions. J. Biol. Chem. 2014, 289, 24898-24910.

75. Vortkamp, A.; Lee, K.; Lanske, B.; Segre, G.V.; Kronenberg, H.M.; Tabin, C.J. Regulation of rate of cartilage differentiation by Indian hedgehog and PTH-related protein. Science 1996, 273, 613-622.

76. Karp, S.J.; Schipani, E.; St.-Jacques, B.; Hunzelman, J.; Kronenberg, H.; McMahon, A.P. Indian hedgehog coordinates endochondral bone growth and morphogenesis via parathyroid hormone related-protein-dependent and -independent pathways. Development 2000, 127, 543-548.

77. Kawashima-Ohya, Y.; Satakeda, H.; Kuruta, Y.; Kawamoto, T.; Yan, W.; Akagawa, Y.; Hayakawa, T.; Noshiro, M.; Okada, Y.; Nakamura, S. Effects of parathyroid hormone (PTH) and PTH-related peptide on expressions of matrix metalloproteinase-2, -3 , and -9 in growth plate chondrocyte cultures. Endocrinology 1998, 139, 2120-2127.

78. Lanske, B.; Amling, M.; Neff, L.; Guiducci, J.; Baron, R.; Kronenberg, H.M. Ablation of the PTHrP gene or the PTH/PTHrP receptor gene leads to distinct abnormalities in bone development. J. Clin. Investig. 1999, 104, 399-407.

79. Mak, K.K.; Kronenberg, H.M.; Chuang, P.T.; Mackem, S.; Yang, Y. Indian hedgehog signals independently of PTHrP to promote chondrocyte hypertrophy. Development 2008, 135, 1947-1956. 
80. Amizuka, N.; Henderson, J.E.; Hoshi, K.; Warshawsky, H.; Ozawa, H.; Goltzman, D.; Karaplis, A.C. Programmed cell death of chondrocytes and aberrant chondrogenesis in mice homozygous for parathyroid hormone-related peptide gene deletion. Endocrinology 1996, 137, 5055-5067.

81. Weir, E.C.; Philbrick, W.M.; Amling, M.; Neff, L.A.; Baron, R.; Broadus, A.E. Targeted overexpression of parathyroid hormone-related peptide in chondrocytes causes chondrodysplasia and delayed endochondral bone formation. Proc. Natl. Acad. Sci. USA 1996, 93, 10240-10345.

82. Jiang, J.; Leong, N.L.; Mung, J.C.; Hidaka, C.; Lu, H.H. Interaction between zonal populations of articular chondrocytes suppresses chondrocyte mineralization and this process is mediated by PTHrP. Osteoarthr. Cartil. 2008, 16, 70-82.

83. Fischer, J.; Dickhut, A.; Rickert, M.; Richter, W. Human articular chondrocytes secrete parathyroid hormone-related protein and inhibit hypertrophy of mesenchymal stem cells in coculture during chondrogenesis. Arthritis Rheumatol. 2010, 62, 2696-2706.

84. Fischer, J.; Aulmann, A.; Dexheimer, V.; Grossner, T.; Richter, W. Intermittent PTHrP(1-34) exposure augments chondrogenesis and reduces hypertrophy of mesenchymal stromal cells. Stem Cells Dev. 2014, 23, 2513-2523.

85. Mueller, M.B.; Fischer, M.; Zellner, J.; Berner, A.; Dienstknecht, T.; Kujat, R.; Prantl, L.; Nerlich, M.; Tuan, R.S.; Angele, P. Effect of parathyroid hormone-related protein in an in vitro hypertrophy model for mesenchymal stem cell chondrogenesis. Int. Orthop. 2013, 37, 945-951.

86. Kim, Y.J.; Kim, H.J.; Im, G.I. PTHrP promotes chondrogenesis and suppresses hypertrophy from both bone marrow-derived and adipose tissue-derived MSCs. Biochem. Biophys. Res. Commun. 2008, 373, 104-108.

87. Kafienah, W.; Mistry, S.; Dickinson, S.C.; Sims, T.J.; Learmonth, I.; Hollander, A.P. Three-dimensional cartilage tissue engineering using adult stem cells from osteoarthritis patients. Arthritis Rheumatol. 2007, 56, 177-187.

88. Lanske, B.; Karaplis, A.C.; Lee, K.; Luz, A.; Vortkamp, A.; Pirro, A.; Karperien, M.; Defize, L.H.; Ho, C.; Mulligan, R.C.; et al. PTH/PTHrP receptor in early development and Indian hedgehog-regulated bone growth. Science 1996, 273, 663-666.

89. Lee, J.M.; Im, G.I. PTHrP isoforms have differing effect on chondrogenic differentiation and hypertrophy of mesenchymal stem cells. Biochem. Biophys. Res. Commun. 2012, 421, 819-824.

90. Bian, L.; Zhai, D.Y.; Tous, E.; Rai, R.; Mauck, R.L.; Burdick, J.A. Enhanced MSC chondrogenesis following delivery of TGF- $\beta 3$ from alginate microspheres within hyaluronic acid hydrogels in vitro and in vivo. Biomaterials 2011, 32, 6425-6434.

91. Guo, X.; Mak, K.K.; Taketo, M.M.; Yang, Y. The Wnt/ $\beta$-catenin pathway interacts differentially with PTHrP signaling to control chondrocyte hypertrophy and final maturation. PLOS ONE 2009, 4, e6067.

92. Ellman, M.B.; Yan, D.; Ahmadinia, K.; Chen, D.; An, H.S.; Im, H.J. Fibroblast growth factor control of cartilage homeostasis. J. Cell. Biochem. 2013, 114, 735-742.

93. Davidson, D.; Blanc, A.; Filion, D.; Wang, H.; Plut, P.; Pfeffer, G.; Buschmann, M.D.; Henderson, J.E. Fibroblast growth factor (FGF) 18 signals through FGF receptor 3 to promote chondrogenesis. J. Biol. Chem. 2005, 280, 20509-20515. 
94. Chia, S.L.; Sawaji, Y.; Burleigh, A.; McLean, C.; Inglis, J.; Saklatvala, J.; Vincent, T. Fibroblast growth factor 2 is an intrinsic chondroprotective agent that suppresses ADAMTS-5 and delays cartilage degradation in murine osteoarthritis. Arthritis Rheumatol. 2009, 60, 2019-2027.

95. Hung, I.H.; Yu, K.; Lavine, K.J.; Ornitz, D.M. FGF9 regulates early hypertrophic chondrocyte differentiation and skeletal vascularization in the developing stylopod. Dev. Biol. 2007, 307, $300-313$.

96. Lewandoski, M.; Sun, X.; Martin, G.R. Fgf8 signalling from the AER is essential for normal limb development. Nat. Genet. 2000, 26, 460-463.

97. Montero, A.; Okada, Y.; Tomita, M.; Ito, M.; Tsurukami, H.; Nakamura, T.; Doetschman, T.; Coffin, J.D.; Hurley, M.M. Disruption of the fibroblast growth factor-2 gene results in decreased bone mass and bone formation. J. Clin. Investig. 2000, 105, 1085-1093.

98. Yan, D.; Chen, D.; Im, H.J. Fibroblast growth factor-2 promotes catabolism via FGFR1-Ras-RafMEK1/2-ERK1/2 axis that coordinates with the PKCdelta pathway in human articular chondrocytes. J. Cell. Biochem. 2012, 113, 2856-2865.

99. Uchii, M.; Tamura, T.; Suda, T.; Kakuni, M.; Tanaka, A.; Miki, I. Role of fibroblast growth factor 8 (FGF8) in animal models of osteoarthritis. Arthritis Res. Ther. 2008, 10, R90.

100. Liu, Z.; Lavine, K.J.; Hung, I.H.; Ornitz, D.M. FGF18 is required for early chondrocyte proliferation, hypertrophy and vascular invasion of the growth plate. Dev. Biol. 2007, 302, 80-91.

101. Narayana, J.; Horton, W.A. FGFR3 biology and skeletal disease. Connect. Tissue Res. 2015, 29, $1-7$.

102. Shung, C.Y.; Ota, S.; Zhou, Z.Q.; Keene, D.R.; Hurlin, P.J. Disruption of a Sox9- $\beta$-catenin circuit by mutant Fgfr3 in thanatophoric dysplasia type II. Hum. Mol. Genet. 2012, 21, 4628-4644.

103. Maruyama, T.; Mirando, A.J.; Deng, C.X.; Hsu, W. The balance of WNT and FGF signaling influences mesenchymal stem cell fate during skeletal development. Sci. Signal. 2010, 3, ra40.

104. Minina, E.; Kreschel, C.; Naski, M.C.; Ornitz, D.M.; Vortkamp, A. Interaction of FGF, Ihh/Pthlh, and BMP signaling integrates chondrocyte proliferation and hypertrophic differentiation. Dev. Cell 2002, 3, 439-449.

105. Yoon, B.S.; Pogue, R.; Ovchinnikov, D.A.; Yoshii, I.; Mishina, Y.; Behringer, R.R.; Lyons, K.M. BMPs regulate multiple aspects of growth-plate chondrogenesis through opposing actions on FGF pathways. Development 2006, 133, 4667-4678.

106. Colvin, J.S.; Bohne, B.A.; Harding, G.W.; McEwen, D.G.; Ornitz, D.M. Skeletal overgrowth and deafness in mice lacking fibroblast growth factor receptor 3. Nat. Genet. 1996, 12, 390-397.

107. Parker, E.A.; Hegde, A.; Buckley, M.; Barnes, K.M.; Baron, J.; Nilsson, O. Spatial and temporal regulation of GH-IGF-related gene expression in growth plate cartilage. J. Endocrinol. 2007, 194, 31-40.

108. Hunziker, E.B.; Wagner, J.; Zapf, J. Differential effects of insulin-like growth factor I and growth hormone on developmental stages of rat growth plate chondrocytes in vivo. J. Clin. Investig. 1994, 93, 1078-1086.

109. Middleton, J.; Manthey, A.; Tyler, J. Insulin-like growth factor (IGF) receptor, IGF-I, interleukin-1 $\beta$ (IL-1 $\beta$ ), and IL-6 mRNA expression in osteoarthritic and normal human cartilage. J. Histochem. Cytochem. 1996, 44, 133-141. 
110. Abbaspour, A.; Takata, S.; Matsui, Y.; Katoh, S.; Takahashi, M.; Yasui, N. Continuous infusion of insulin-like growth factor-I into the epiphysis of the tibia. Int. Orthop. 2008, 32, 395-402.

111. Longobardi, L.; Granero-Moltó, F.; O’Rear, L.; Myers, T.J.; Li, T.; Kregor, P.J.; Spagnoli, A. Subcellular localization of IRS-1 in IGF-I-mediated chondrogenic proliferation, differentiation and hypertrophy of bone marrow mesenchymal stem cells. Growth Factors 2009, 27, 309-320.

112. Cucchiarini, M.; Madry, H. Overexpression of human IGF-I via direct rAAV-mediated gene transfer improves the early repair of articular cartilage defects in vivo. Gene Ther. 2014, 21, 811-819.

113. Wang, J.; Zhou, J.; Bondy, C.A. Igf1 promotes longitudinal bone growth by insulin-like actions augmenting chondrocyte hypertrophy. FASEB J. 1999, 13, 1985-1990.

114. Repudi, S.R.; Patra, M.; Sen, M. WISP3-IGF1 interaction regulates chondrocyte hypertrophy. J. Cell Sci. 2013, 126, 1650-1658.

115. Mushtaq, T.; Bijman, P.; Ahmed, S.F.; Farquharson, C. Insulin-like growth factor-I augments chondrocyte hypertrophy and reverses glucocorticoid-mediated growth retardation in fetal mice metatarsal cultures. Endocrinology 2004, 145, 2478-2486.

116. Bohme, K.; Conscience-Egli, M.; Tschan, T.; Winterhalter, K.H.; Bruckner, P. Induction of proliferation or hypertrophy of chondrocytes in serum-free culture: The role of insulin-like growth factor-I, insulin, or thyroxine. J. Cell Biol. 1992, 116, 1035-1042.

117. Wang, L.; Shao, Y.Y.; Ballock, R.T. Thyroid hormone-mediated growth and differentiation of growth plate chondrocytes involves IGF-1 modulation of $\beta$-catenin signaling. J. Bone Miner. Res. 2010, 25, 1138-1146.

118. Wang, Y.; Nishida, S.; Sakata, T.; Elalieh, H.Z.; Chang, W.; Halloran, B.P.; Doty, S.B.; Bikle, D.D. Insulin-like growth factor-I is essential for embryonic bone development. Endocrinology 2006, 147, 4753-4761.

119. Silver, I.A. Measurement of $\mathrm{pH}$ and ionic composition of pericellular sites. Philos. Trans. R. Soc. Lond. B Biol. Sci. 1975, 271, 261-272.

120. Leijten, J.; Georgi, N.; Teixeira, L.M.; van Blitterswijk, C.A.; Post, J.N.; Karperien, M. Metabolic programming of mesenchymal stromal cells by oxygen tension directs chondrogenic cell fate. Proc. Natl. Acad. Sci. USA 2014, 111, 13954-13959.

121. Lee, H.H.; Chang, C.C.; Shieh, M.J.; Wang, J.P.; Chen, Y.T.; Young, T.H.; Hung, S.C. Hypoxia enhances chondrogenesis and prevents terminal differentiation through PI3K/Akt/FoxO dependent anti-apoptotic effect. Sci. Rep. 2013, 3, 2683.

122. Mariani, E.; Pulsatelli, L.; Facchini, A. Signaling pathways in cartilage repair. Int. J. Mol. Sci. 2014, $15,8667-8698$.

123. Zhou, N.; Hu, N.; Liao, J.Y.; Lin, L.B.; Zhao, C.; Si, W.K.; Yang, Z.; Yi, S.X.; Fan, T.X.; Bao, W.; et al. HIF-1 $\alpha$ as a regulator of BMP2-induced chondrogenic differentiation, osteogenic differentiation, and endochondral ossification in stem cells. Cell. Physiol. Biochem. 2015, 36, 44-60.

124. Saito, T.; Fukai, A.; Mabuchi, A.; Ikeda, T.; Yano, F.; Ohba, S.; Nishida, N.; Akune, T.; Yoshimura, N.; Nakagawa, T.; et al. Transcriptional regulation of endochondral ossification by HIF-2 $\alpha$ during skeletal growth and osteoarthritis development. Nat. Med. 2010, 16, 678-686.

125. Yang, S.; Kim, J.; Ryu, J.H.; Oh, H.; Chun, C.H.; Kim, B.J.; Min, B.H.; Chun, J.S. Hypoxia-inducible factor- $2 \alpha$ is a catabolic regulator of osteoarthritic cartilage destruction. Nat. Med. 2010, 16, 687-693. 
126. Wu, L.; Huang, X.; Li, L.; Huang, H.; Xu, R.; Luyten, W. Insights on biology and pathology of HIF-1 $\alpha /-2 \alpha$, TGF $\beta / B M P$, Wnt/ $\beta$-catenin, and NF-kB pathways in osteoarthritis. Curr. Pharm. Des. 2012, 18, 3293-3312.

127. Tamiya, H.; Ikeda, T.; Jeong, J.H.; Saito, T.; Yano, F.; Jung, Y.K.; Ohba, S.; Kawaguchi, H.; Chung, U.I.; Choi, J.Y. Analysis of the Runx2 promoter in osseous and non-osseous cells and identification of HIF2A as a potent transcription activator. Gene 2008, 416, 53-60.

128. Yang, S.; Ryu, J.H.; Oh, H.; Jeon, J.; Kwak, J.S.; Kim, J.H.; Kim, H.A.; Chun, C.H.; Chun, J.S. NAMPT (visfatin), a direct target of hypoxia-inducible factor- $2 \alpha$, is an essential catabolic regulator of osteoarthritis. Ann. Rheum. Dis. 2015, 74, 595-602.

129. Ryu, J.H.; Shin, Y.; Huh, Y.H.; Yang, S.; Chun, C.-H.; Chun, J.-S. Hypoxia-inducible factor-2 $\alpha$ regulates Fas-mediated chondrocyte apoptosis during osteoarthritic cartilage destruction. Cell Death Differ. 2012, 19, 440-450.

130. Lafont, J.E.; Talma, S.; Murphy, C.L. Hypoxia-inducible factor $2 \alpha$ is essential for hypoxic induction of the human articular chondrocyte phenotype. Arthritis Rheumatol. 2007, 56, 3297-3306.

(C) 2015 by the authors; licensee MDPI, Basel, Switzerland. This article is an open access article distributed under the terms and conditions of the Creative Commons Attribution license (http://creativecommons.org/licenses/by/4.0/). 